\title{
Teachers' Self-efficacy in Preventing and Intervening in School Bullying: a Systematic Review
}

\author{
Saskia M. Fischer ${ }^{1}$ (D) $\cdot$ Nancy John ${ }^{1} \cdot$ Ludwig Bilz $^{1}$ (C)
}

Published online: 21 August 2020

(C) The Author(s) 2020

\begin{abstract}
Self-efficacy, commonly seen as an important competence for teachers when intervening in bullying, is a heterogeneous construct. Differences in the specific kinds of self-efficacy under review, its assessment, theoretical foundations, and the samples used when researching it generate diverse results that can be hard to integrate. This systematic review surveys existing literature on the extent of teachers' self-efficacy in managing bullying and its connection to the likelihood that teachers will intervene in bullying, to their intervention strategies, and the prevention measures they employ, as well as students' bullying behavior and their experiences of victimization. Thirty-six relevant publications based on 33 studies were included. The quality of their results was assessed, and their findings were systematized and are discussed here. Many studies are of low quality because of incomplete descriptions of underlying theoretical as well as methodological foundations. Almost all results are based on descriptive study designs. Consistent findings show that teachers generally feel confident in managing bullying and that teachers who are more confident intervene more often. Findings were mixed on the connections between teachers' self-efficacy and intervention strategies, and the prevention measures they used, as well as students' bullying behavior and experiences of victimization. It was also discovered that the connections between teachers' self-efficacy and their prevention measures, their students' bullying behavior, and collective efficacy in general have rarely been addressed in the literature.
\end{abstract}

Keywords School bullying $\cdot$ Teachers $\cdot$ Self-efficacy $\cdot$ Bullying prevention $\cdot$ Bullying intervention

\section{Introduction}

Bullying is usually defined as a particular form of aggressive behavior that is repeatedly carried out over a long period of time with the intention of causing harm. There is a power imbalance between the participants, which makes it difficult for the students who are bullied to defend themselves (Olweus 1994). The frequency of bullying in schools varies widely between countries, with up to $35 \%$ of learners experiencing bullying (Modecki et al. 2014). Negative consequences of bullying can affect health, performance, and social

Electronic supplementary material The online version of this article (https://doi.org/10.1007/s42380-020-00079-y) contains supplementary material, which is available to authorized users.

Saskia M. Fischer

saskia.fischer@b-tu.de

1 Department of Health Sciences, Brandenburg University of Technology Cottbus-Senftenberg, Universitätsplatz 1, 01968 Senftenberg, Germany relationships, which in some cases can last into adulthood (Gini and Pozzoli 2013; Klomek et al. 2013; Takizawa et al. 2014).

Bullying does not only take place between two students but develops within a framework of complex social interactions that involve different groups of people (Azeredo et al. 2015; Hong and Espelage 2012). Due to the power imbalance, the bullying victim generally requires a third party to stop the bullying process. In bullying among students, teachers can represent such a third party (Oldenburg et al. 2015; Saarento et al. 2015). Several studies indicate that teachers with higher self-efficacy beliefs intervene more often in bullying situations (Bradshaw et al. 2007; Duong and Bradshaw 2013; Williford and Depaolis 2016).

\section{Self-efficacy in Teachers}

Self-efficacy is an interdisciplinary concept that has different meanings in different contexts. Generally, it refers to a person's conviction that they have sufficient competences to successfully master given requirements (Bandura 1994). General 
self-efficacy describes one's general conviction regarding one's own competences (Scholz et al. 2002; Schwarzer and Jerusalem 2002). Domain-specific forms of self-efficacy refer to competences in specific roles or areas of responsibility (e.g., teacher self-efficacy, which is the conviction in teachers that they successfully meet professional requirements) (Schwarzer and Jerusalem 2002; Schwarzer and Warner 2014). Selfefficacy in relation to a specific task within domain-specific self-efficacy beliefs is called situation-specific or task-specific self-efficacy (e.g., confidence of handling a bullying situation) (Schwarzer and Warner 2014).

Self-efficacy can be assessed both individually and collectively. Individual self-efficacy refers to one's own expectations regarding one's own competencies, whereas collective self-efficacy refers to the expectation that a group can act effectively together (Bandura 1994; Schwarzer and Warner 2014). Most empirical work on self-efficacy refers to individual self-efficacy (Hymel et al. 2015; Schwarzer and Warner 2014).

Individual teacher self-efficacy has been identified in various works as an important part of teacher's behavior (e.g., Bandura 1994; Schwarzer and Jerusalem 2002; Schwarzer and Warner 2014; Zee and Koomen 2016). However, the application of a diverse array of different survey instruments makes it difficult to compare the numerous results that exist in the literature (Schmitz and Schwarzer 2000; TschannenMoran and Woolfolk Hoy 2001). A measure of self-efficacy that is as specific as possible and related to various concrete tasks is often regarded as advantageous (Bandura 1977; Schmitz and Schwarzer 2000; Tschannen-Moran and Woolfolk Hoy 2001). However, a number of instruments measure self-efficacy on a general level and sometimes with only one item.

\section{Self-efficacy of Teachers in the Context of Bullying}

An oft-cited study by Bradshaw et al. (2007) shows that teachers with higher individual self-efficacy beliefs intervene more often in bullying situations. But the study has some methodological limitations (e.g., incomplete descriptions of measures and statistical analyses). According to Duong and Bradshaw (2013), as well as Williford and Depaolis (2016), the study's results can be replicated in school staff samples. Begotti et al. (2017), on the other hand, did not find a connection between teachers' self-efficacy and the likelihood that they would intervene in bullying in a sample of kindergarten, primary school, and secondary school teachers. While bullying in preschool and in school share a number of common elements, they also vary in several important aspects, such as in the distinction of participant roles (Camodeca et al. 2015). Could the differences between the results be based on differences between the samples used in the studies? And how are self-efficacy and the likelihood of intervention connected in samples that exclusively include school teachers?

When teachers intervene in bullying, they have to choose from a variety of strategies, some of which are considered to be more successful than others (e.g., Wachs et al. 2019). Do teachers with higher self-efficacy beliefs choose different strategies than teachers with lower self-efficacy beliefs? Yoon et al. (2016) did not find any such connection when they asked preschool teachers and school teachers to describe how they would react to a described bullying scenario. Can these findings be replicated in samples that only include school teachers?

As shown above, teachers should feel confident if they are going to be able to successfully intervene in bullying. However, several studies report that both in-service and preservice teachers feel ill-prepared to handle bullying and express a desire to receive further training in bullying prevention and intervention strategies (e.g., Blain-Arcaro et al. 2012; Kennedy et al. 2012). Is this finding reflected in the low self-efficacy beliefs of the teachers in question?

\section{The Current Study}

With this systematic review, the current state of literature concerning teachers' self-efficacy in bullying prevention and intervention is reviewed and systematized. In particular, three research questions guided the review procedure:

Research question 1: What types of self-efficacy are assessed in the context of bullying prevention and intervention at school and which theoretical foundations are used?

Research question 2: How confident are teachers concerning their skills in preventing and intervening in bullying at school?

Research question 3: What empirical findings exist on the connection between teachers' self-efficacy and bullying-related outcomes, which include a) teachers' likelihood of intervention, b) teachers' intervention strategies, and c) students' bullying behavior and experiences of victimization?

\section{Method}

\section{Search Strategies}

Publications were searched for in the databases Web of Science Core Collection, PsycINFO, Pubpsych (including PSYNDEX, PASCAL, MEDLINE, ERIC), and PubMed. The search term was "bullying AND teacher AND (self-efficacy OR confidence OR efficacy)." In the German databases 
Pubpsych and PubMed, equivalent search terms in German were used. In addition to the database searches, researchers were asked to send unpublished studies and gray literature on teachers' self-efficacy in the context of school bullying. Studies that were published in the databases up to March 30, 2020 , or were sent to one of the authors, were included in the review. Only publications published in English or German were considered. No limits concerning year of publication or type of publication were set.

\section{Inclusion and Exclusion Criteria}

Empirical studies that in any way assessed self-efficacy of teachers in connection to bullying at school among students were included. Results of the studies had to include information on the extent of teachers' self-efficacy, any group differences, or connections between teachers' self-efficacy and a behavioral bullying-related outcome. Exclusion criteria were a focus on the self-efficacy of students, bullying outside of school (e.g., in sports clubs) or a lack of focus on studentteacher contexts (i.e., literature that did not mention teachers at all), the assessment of school staff without specific information concerning teachers, and research summaries or theoretical publications that were not backed up by empirical data. Also excluded were studies that only concerned the improvement of teachers' self-efficacy through training, factors that influence the extent of teachers' self-efficacy, or outcomes that are not bullying-related or action-related (e.g., attitudes towards specific groups of students, attitudes towards or knowledge about bullying). Inclusion and exclusion of studies was rated independently by the first and the second author. The interrater reliability was $\kappa=.82$ for inclusion and exclusion. Every study in which the ratings deviated from each other was discussed and decided upon using a forced choice method.

\section{Assessment of Quality and Level of Conclusiveness}

Assessment of Quality Based on Cochrane's GRADE system, the quality was first determined using a basic evaluation, which could then be upgraded or downgraded according to further criteria. At the end of this process, the quality of the study was rated on a four-level scale (very low, low, moderate, and high). The criteria of this quality assessment were adapted from the quality criteria of the Cochrane Collaboration (Ryan and Hill 2016), the Green List of Prevention (Landespraeventionsrat Niedersachsen 2011), and the German Forum for Crime Prevention (Stiftung Deutsches Forum für Kriminalpraevention 2018). Following the recommendations of the GRADE system, the basic evaluation could either be high (both self-efficacy and bullying were clearly defined, research question focused on teachers' self-efficacy in the bullying context) or low. Basic quality was downgraded if samples or measures were insufficiently described, biased, or when samples were too small (samples below 300; Ryan and Hill 2016). The basic quality was upgraded when results were based on external measures rather than just self-reports, or if results were not based on an explicit research question, but were extensively reported and discussed. The criteria and results of the basic evaluation as well as the criteria used for upgrading and downgrading measures of quality are presented in Online Resource 1 for each publication.

Assessment of Level of Conclusiveness In addition, the level of conclusiveness, which is in turn based on study design, was rated. This assessment followed the approach of the Green List of Prevention (Landespraeventionsrat Niedersachsen 2011) and was based on Veerman and Van Yperen (2007). Depending on the study design, the results could exhibit conclusiveness that was either descriptive (e.g., descriptive studies, correlation studies), theoretical (e.g., reviews and metaanalyses), indicative (e.g., quasi-experimental studies, change measurements), or causal (e.g., RCTs).

\section{Coding System}

Based on the research questions of the review and the quality assessment, several criteria were coded for each publication included in the review. These coding criteria are presented in Table 1.

The coding was conducted independently by the first and the second author. All coding criteria that could be assessed quantitatively (see Table 1) were included in the calculation of the interrater reliability. The interrater reliability for the coding system in relation to these criteria is $\kappa=.79$ (minimum: 0.49 [type of self-efficacy assessed], maximum: 1.00 [access to research approach]). All other criteria (asterisked in Table 1) were compared descriptively according to the content. All codings that differed between the two raters were discussed and decided upon using a forced choice method.

\section{Results}

\section{Results of the Literature Search}

The database searches resulted in 395 hits, with 110 publications occurring more than once. After an application of the inclusion and exclusion criteria to title and abstract, 178 publications were excluded. Nine of the publications considered relevant could not be included in the full text analysis because the full unpublished texts were not available, despite attempts to contact the authors and the institutions in question. A total of 98 publications were included in the full text analysis. Sixty-two publications were excluded from the review in the full text analysis 
Table 1 Coding criteria

Theoretical foundation

Information on self-efficacy

Results

\begin{tabular}{|c|c|}
\hline $\begin{array}{l}\text { Basic information about the } \\
\text { publication }\end{array}$ & $\begin{array}{l}\text { Country of data assessment } \\
\text { Type of publication (e.g., journal article, dissertation) } \\
\text { Research approach (qualitative, quantitative, or mixed methods) }\end{array}$ \\
\hline $\begin{array}{l}\text { Information about study } \\
\text { design }\end{array}$ & $\begin{array}{l}\text { Sample (e.g., pre-service teachers, in-service teachers) } \\
\text { Sample size } \\
\text { Use of a control group } \\
\text { Use of randomization } \\
\text { Description of possible drop-out* } \\
\text { Times of data collection and study design (e.g., RCT with follow-up, } \\
\quad \text { descriptive measure with one data collection)* }\end{array}$ \\
\hline Theoretical foundation & $\begin{array}{l}\text { Definition of bullying } \\
\text { Definition of self-efficacy } \\
\text { Fit between theoretical description and measure of the type of self-efficacy* }\end{array}$ \\
\hline Information on self-efficacy & $\begin{array}{l}\text { Type of self-efficacy assessed (e.g., individual, collective) } \\
\text { Assessment of self-efficacy* } \\
\text { Construct that self-efficacy is related to (e.g., handling bullying) }\end{array}$ \\
\hline Results & $\begin{array}{l}\text { Outcomes that self-efficacy is linked to* } \\
\text { Topic (e.g., general extent of self-efficacy, connection between self-efficacy } \\
\text { and intervention strategies) } \\
\text { Research question(s) that addresses self-efficacy* } \\
\text { Result(s) to this research question(s)* } \\
\text { Discussion and critical reflection of the results presented* }\end{array}$ \\
\hline
\end{tabular}

Criteria marked with asterisk were not assessed quantitatively but described by each rater in own words based on the inclusion criteria not being met. The remaining 36 publications formed the corpus of this review and were fully coded. Figure 1 shows the procedure and results of the literature search.
Fig. 1 Procedure and results of the search for literature

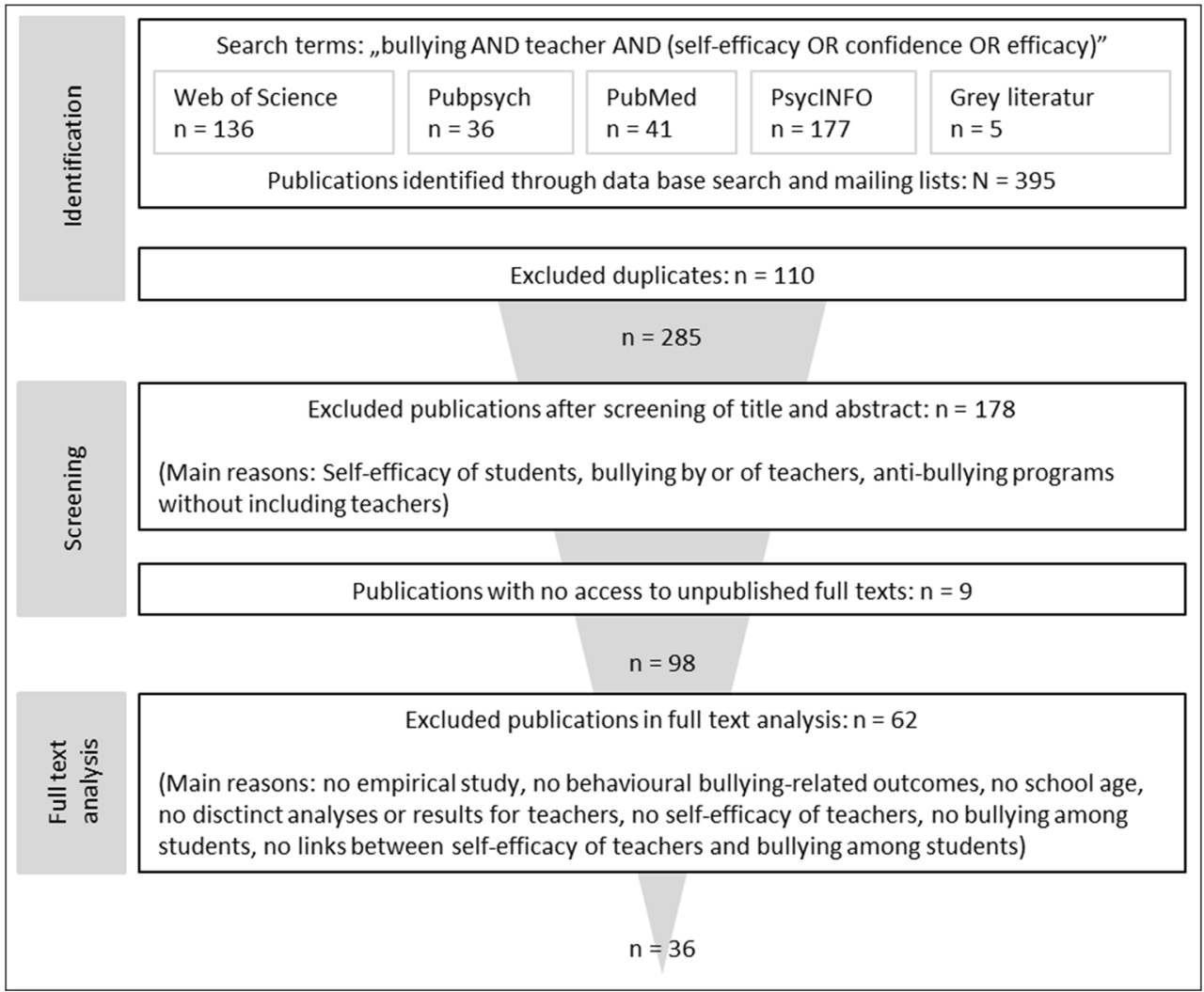




\section{Main Characteristics of the Publications and Studies Included}

The 36 publications that were included in the review were published between 2002 and 2019 and most were published as journal articles. As the quality assessment is based in part on the theoretical foundation outlined above, quality is rated for publications rather than for studies. Most of the 36 publications were rated as very low or low in quality (see Table 4 and Online Resource 1). The main characteristics of the 36 publications are presented in Table 2.

The 36 publications in the review were based on 33 studies (see Table 4). Most of the studies were conducted in the USA, were focused on in-service teachers, and had a sample size of up to 500 participants. Quantitative studies were much more common than qualitative studies. Except for one quantitative study, all studies include results with a descriptive level of conclusiveness. The main characteristics of the studies that were included in the review are presented in Table 3.

An overview of the publications included in the review with their main characteristics and their focus is given in Table 4.

\section{Type and Assessment of Self-efficacy in the Studies}

All but one study assessed individual self-efficacy. Most studies assessed teachers' confidence in intervening in bullying (19 studies). All in all, 76\% of the studies explored a task-

Table 2 Main characteristics of publications $(n=36)$ included in the review

\begin{tabular}{lll}
\hline & $n$ & $\%$ \\
\hline Year & & \\
$2002-2005$ & 3 & 8.3 \\
$2006-2010$ & 4 & 11.1 \\
$2011-2015$ & 10 & 27.8 \\
$2016-2019$ & 19 & 52.8
\end{tabular}

Type of publication

\begin{tabular}{lll} 
Journal article & 25 & 69.4 \\
Dissertation & 8 & 22.2 \\
Book chapter & 1 & 2.8 \\
Congress lecture & 1 & 2.8 \\
Online publication & 1 & 2.8 \\
& & \\
Quality & & \\
Very low & 16 & 44.4 \\
Low & 6 & 16.7 \\
Moderate & 7 & 19.4 \\
High & 3 & 8.3 \\
Not rated* & 4 & 11.1 \\
\hline
\end{tabular}

*Quality is not rated for qualitative studies
Table 3 Main characteristics of studies $(n=33)$ included in the review

n $\%$

Country of data collection

USA

Great Britain

15

$\%$

Italy

Canada

Germany

Australia

Israel

South Korea

Netherlands

Sweden

More than one country:

Ireland and Northern Ireland

Canada and Turkey

Research approach

Quantitative

29

87.9

Qualitative

4

Sample

In-service teachers

19

57.6

Pre-service teachers

21.2

Pre-service and in-service teachers

15.2

In-service teachers and students

6.1

Sample size*

8 to 50

18.2

51 to 100

9.1

101 to 200

33.3

201 to 500

27.3

501 to 1000

6.1

1001 to 2022

6.1

Level of conclusiveness

Descriptive 28

84.8

Theoretical

Indicative

0.0

\section{Causal}

3.0

0.0

Not rated**

12.1

*If both teachers and students were included, the number of teachers is given here

**Level of conclusiveness is not rated for qualitative studies (see Section 2.3)

specific form of self-efficacy. Only eight studies assessed selfefficacy in a domain-specific way. More than $35 \%$ of the studies were based on Bandura's concept of self-efficacy, but $45 \%$ presented no theoretical foundation for self-efficacy. 







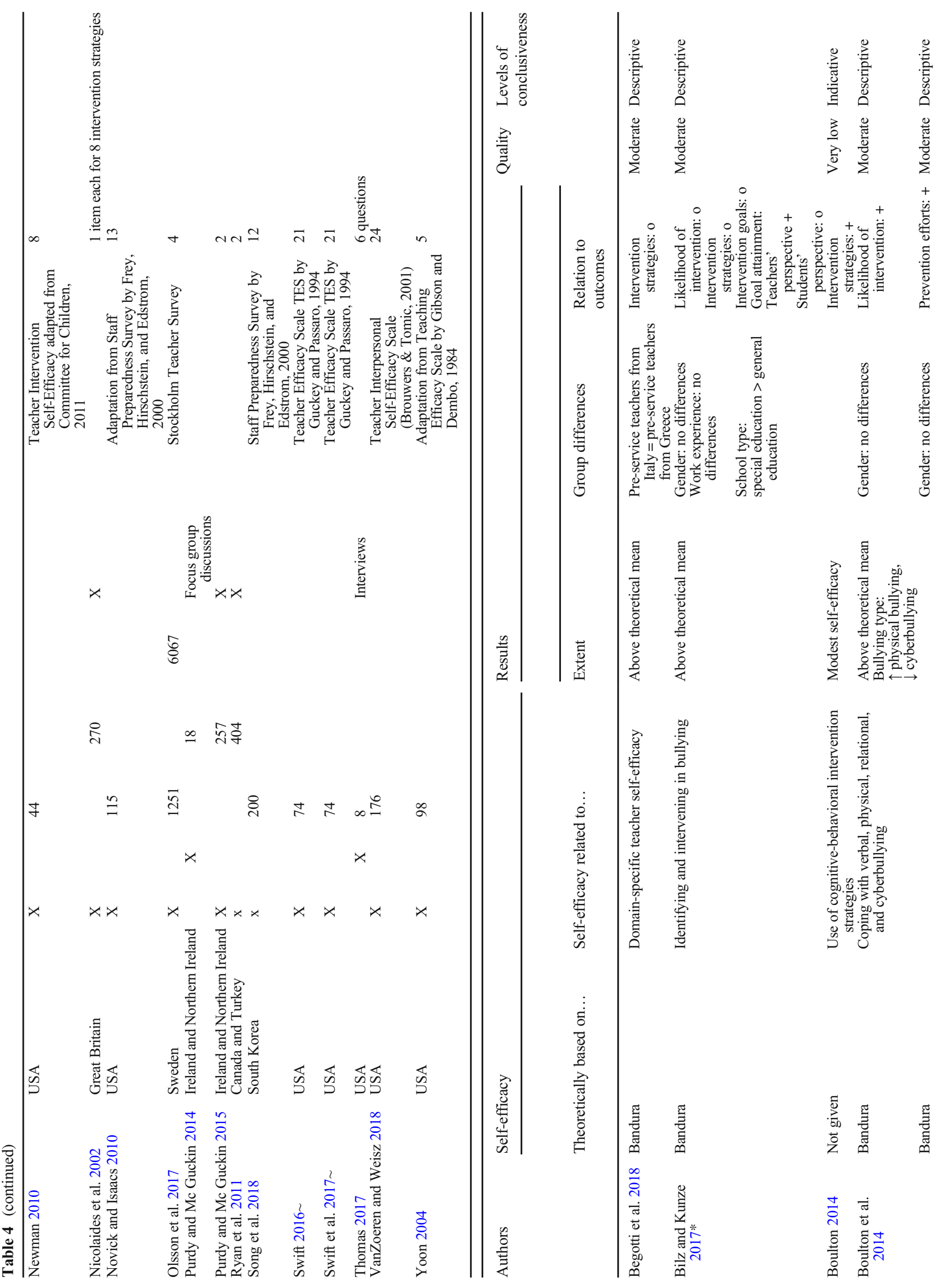




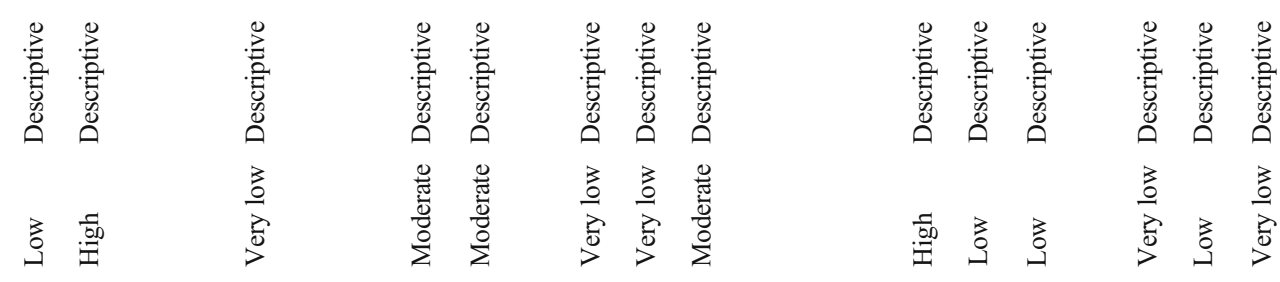

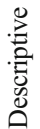

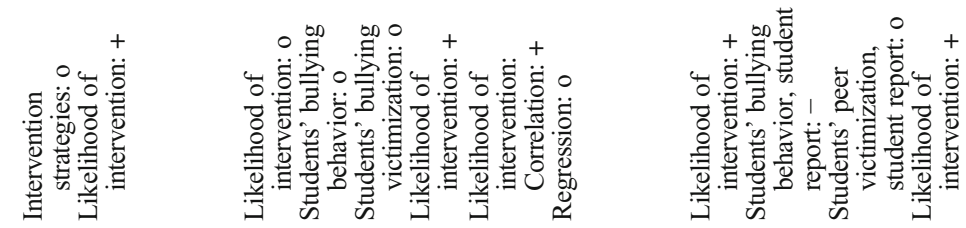
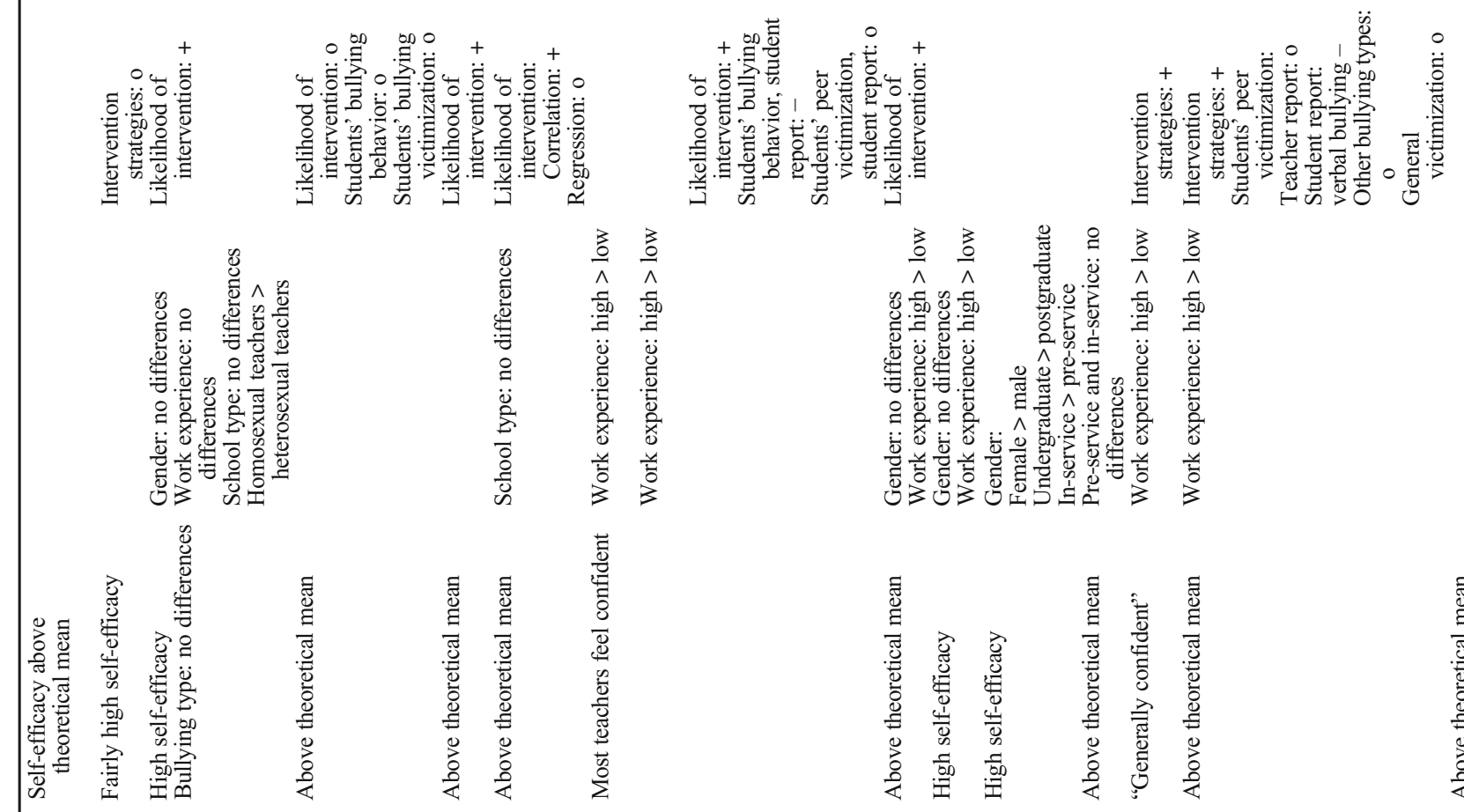

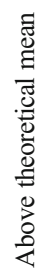
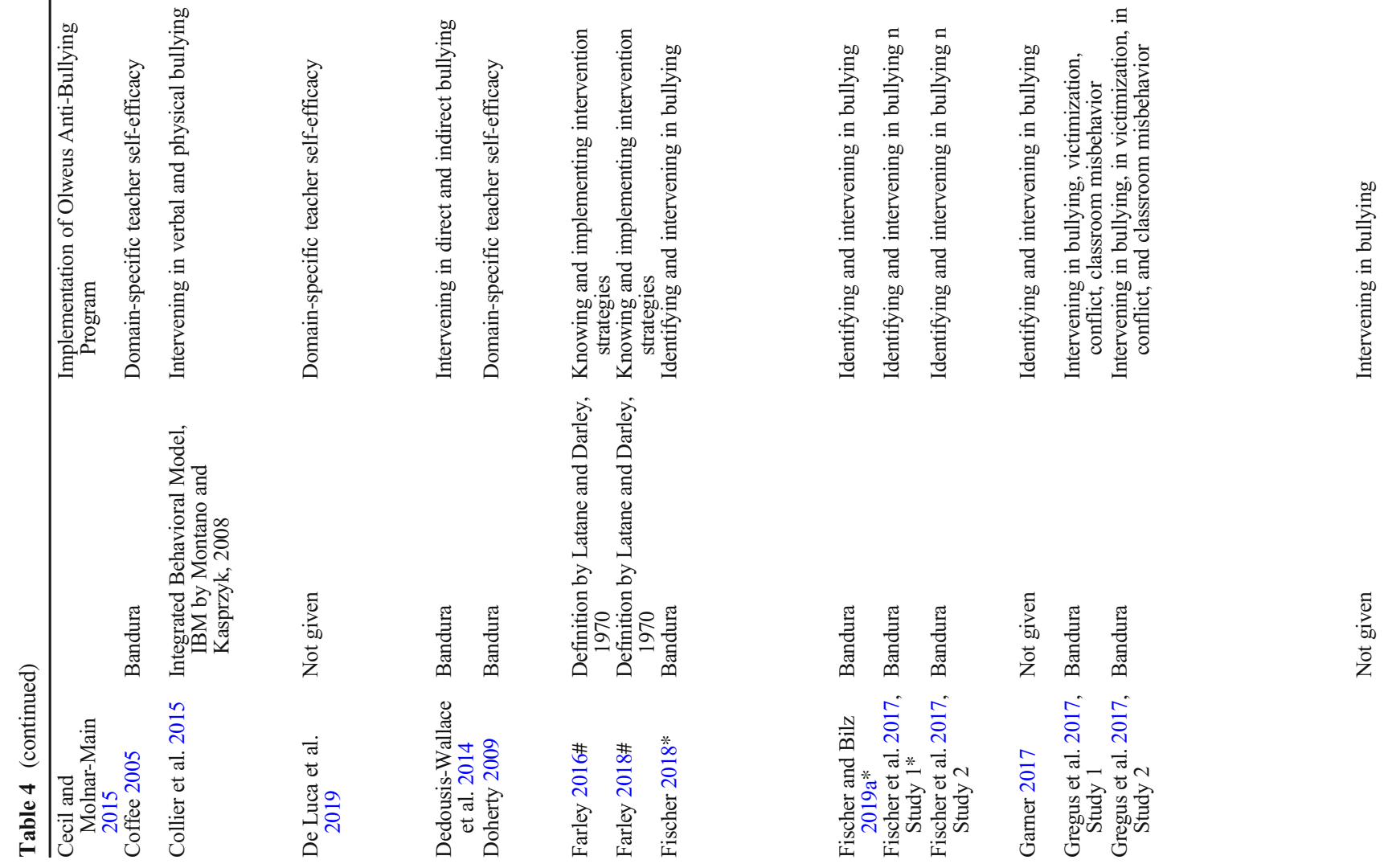

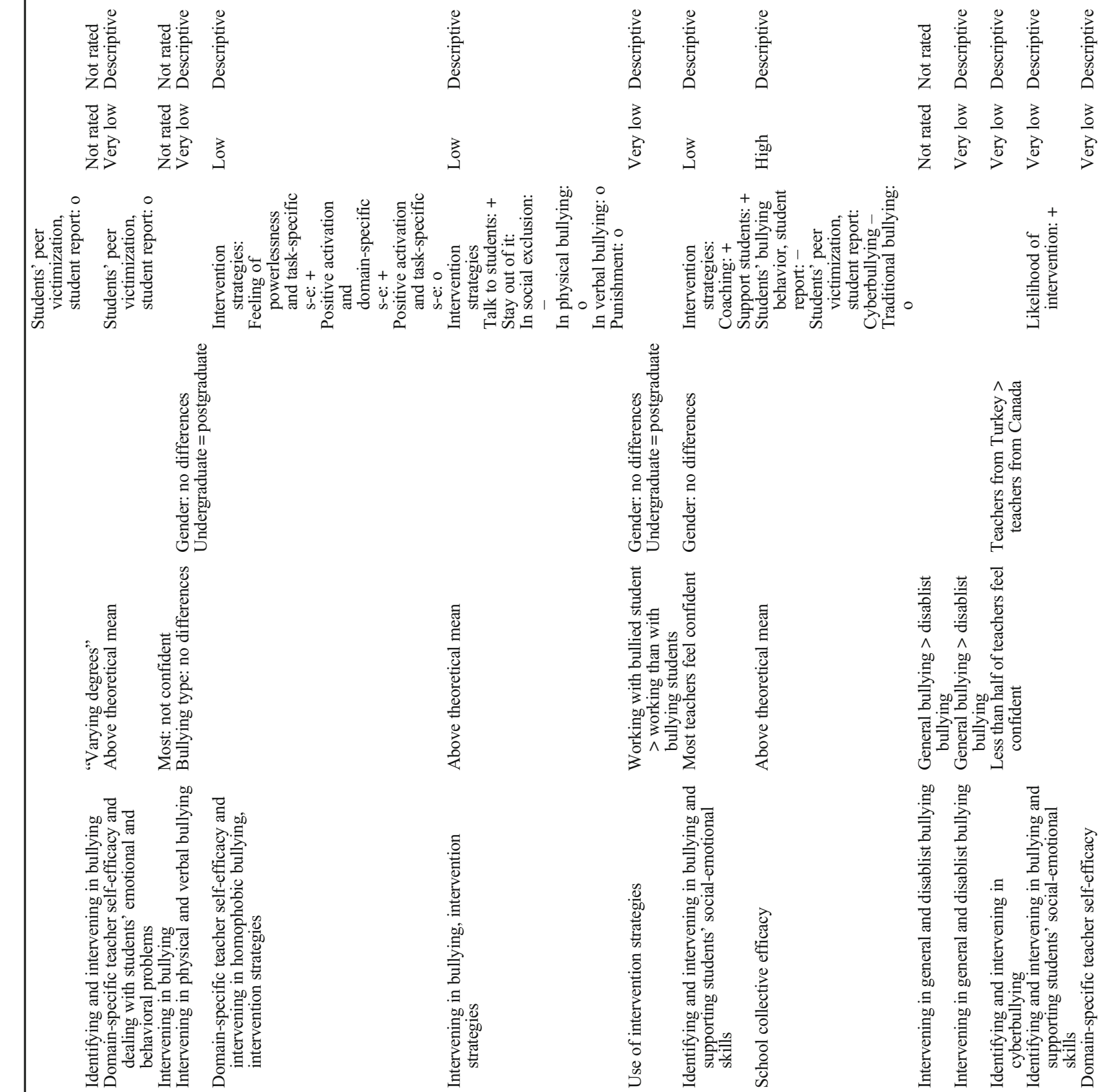

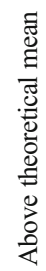
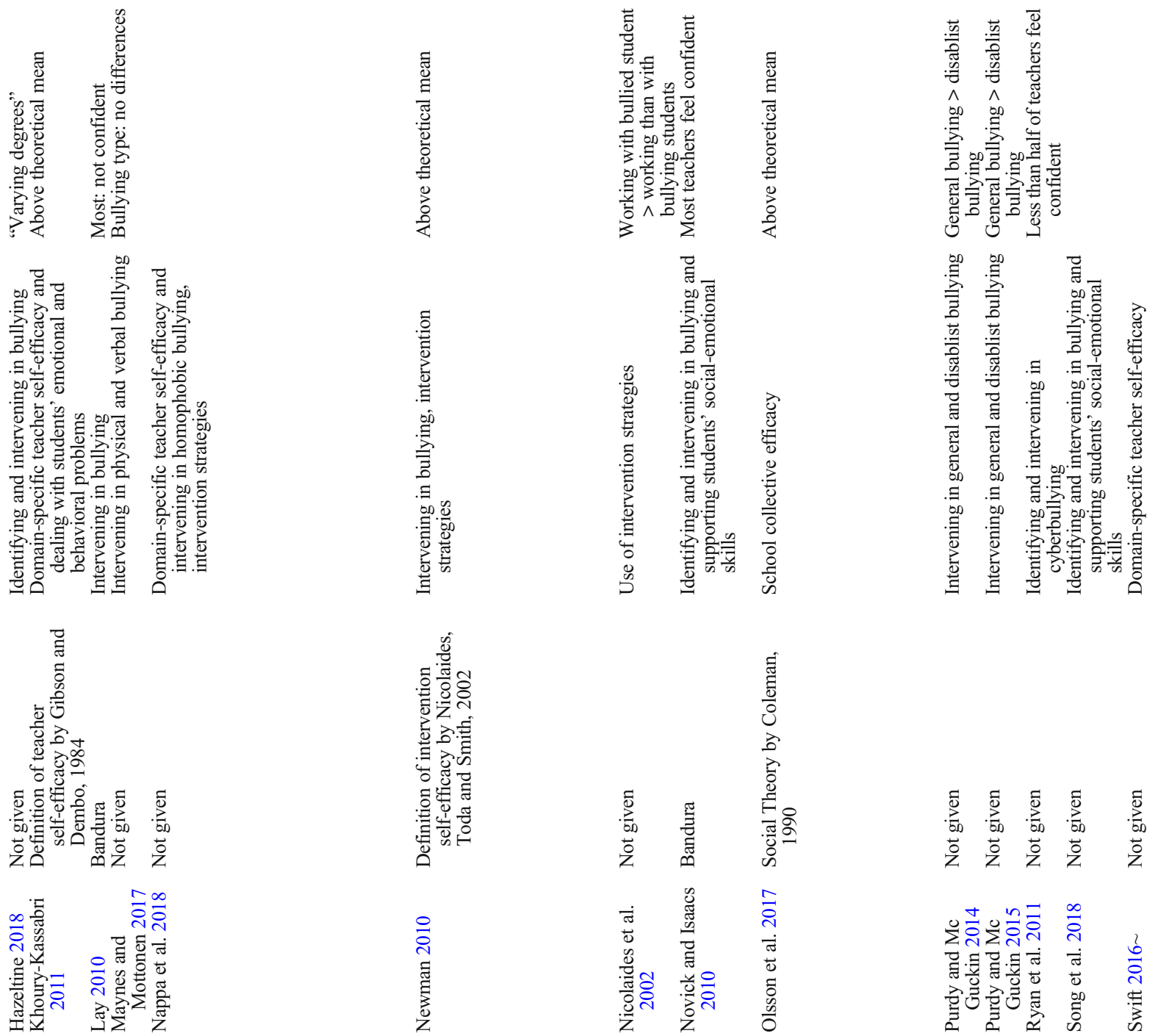
Five studies were based on a definition or theory of selfefficacy other than that presented by Bandura (see Table 4).

The assessment of self-efficacy was very heterogeneous with the number of items ranging between 2 and 24 (see Table 4). In $42 \%$ of the studies, self-efficacy was assessed using new quantitative measures that were developed by the authors in question. In $45 \%$ of the studies, self-efficacy was assessed with a total of 15 different scales that were previously published by authors other than the study authors. All in all, no typical scale for the assessment of self-efficacy was used.

\section{Extent of Teachers' Self-efficacy in Bullying Interventions}

General extent. (25 studies) For most studies (20 studies), means of scale were presented. Every single mean was above the theoretical mean of scale. In seven quantitative studies, the authors explicitly interpreted the general extent of selfefficacy as high (see Table 4).

In qualitative studies, teachers seem to express a lower level of self-efficacy than they do in quantitative studies. In three of the four qualitative studies, researchers presented information on the general extent of teachers' self-efficacy, which is low for some teachers. Participants explicitly said that they were unsure if they could successfully intervene in bullying (Hazeltine 2018; Thomas 2017). In one study, even $70 \%$ of the teachers expressed such insecurities (Lay 2010).

It is not clear if teachers felt more confident in handling particular types of bullying than others. While one study found that teachers felt most confident in handling physical bullying (Boulton et al. 2014), another study found no such difference (Collier et al. 2015). Findings from single studies indicate that teachers may feel less confident in working with students who bully (Nicolaides et al. 2002), in handling cyberbullying (Boulton et al. 2014) and bullying outside school grounds (Maynes and Mottonen 2017), and in handling special cases of bullying (e.g., disablist bullying; Purdy and Mc Guckin 2014, 2015).

In summary, teachers seem to feel quite confident in identifying and managing bullying. But teachers express lower levels of self-efficacy in interviews than in quantitative studies. The literature is not consistent and extensive enough for us to be able to say that teachers feel more confident in dealing with some forms of bullying than with others.

Group differences. Gender differences. (8 studies) In seven studies, no gender differences were found within samples of in-service teachers and pre-service teachers. Only one study reported that the female teachers had higher levels of selfefficacy than male teachers (Fischer et al. 2017, Study 2).

Differences in work experience. (5 studies) In three studies, teachers with more work experience reported higher selfefficacy beliefs. One study found differences in teachers' self-efficacy when it came to work experience (Collier et al. 
2015). In another study, the connection between work experience and self-efficacy was dependent on the statistical analyses used, with most results indicating that highly experienced teachers had a higher sense of self-efficacy compared with teachers with less work experience (Fischer and Bilz 2019a; Fischer et al. 2017, Study 1).

Differences in school type. (3 studies) In two studies, no differences were found between teachers in special education and teachers in general education (Collier et al. 2015; Doherty 2009). One study found that teachers from schools for children with special needs reported higher self-efficacy than teachers from academic-track general education schools (i.e., schools that aim to prepare students for university studies) (Bilz and Kunze 2017, also reported in Fischer et al. 2017).

Other group differences. Two studies investigated if preservice teachers and in-service teachers differed in their selfefficacy. While one low-quality study reported that in-service teachers had higher self-efficacy beliefs when it came to identifying and investigating bullying than pre-service teachers (Fischer et al. 2017), another very low-quality study found no such differences (Garner 2017). The question of whether pre-service teachers who received their training at a postgraduate level differed from pre-service teachers who received their training at an undergraduate level was investigated in three separate studies with very mixed results. In one study, students in an educational undergraduate course reported higher levels of self-efficacy than students in a postgraduate course (Fischer et al. 2017, Study 2). In another study, preservice teachers attending a "consecutive" course (involving intensive training over 8 months and then 13 weeks of practical training) had higher self-efficacy beliefs than pre-service teachers attending a "concurrent" 5 -year undergraduate course (Maynes and Mottonen 2017). A third study, however, found no differences between pre-service teachers attending undergraduate or postgraduate courses (Nicolaides et al. 2002). Three more studies investigated whether teachers differ in their self-efficacy depending on their belonging to a sexual minority or depending on the country they come from (Begotti et al. 2018; Collier et al. 2015; Ryan et al. 2011; for results see Table 4).

In summary, most studies indicated that male and female teachers do not differ in their self-efficacy beliefs, while teachers with more work experience tend to be more confident in handling bullying. Because of how heterogeneous the results are, it cannot be said with any certainty whether teachers' self-efficacy differs between school types and between preservice and in-service teachers.

\section{Connections Between Teachers' Self-efficacy and Bullying-Related Outcomes}

Likelihood that teachers will intervene. (9 studies) In five studies, teachers with higher self-efficacy beliefs intervened more often in bullying situations than teachers with lower selfefficacy beliefs. In three studies, the results differed according to the statistical analyses used. Using chi-squared tests, Bilz and Kunze (2017) found no connection between a categorized self-efficacy and teachers' likelihood of intervention. When analyzing the same data in regression analyses with a continuous factor of self-efficacy, higher self-efficacy was connected to a higher likelihood of intervention (Fischer 2018, also reported in Fischer and Bilz 2019a). In the data presented by Doherty (2009), teachers' self-efficacy was correlated with the likelihood that they would intervene in bullying situations. But when Doherty (2009) analyzed this connection in a regression analysis, together with several control variables (e.g., age, gender, work experience), self-efficacy was not shown to be a significant predictor for the likelihood of intervention. Similar results were presented by VanZoeren and Weisz (2018). Only De Luca et al. (2019) found no association between teachers' self-efficacy and their likelihood of intervention, whether in correlation analyses or in a path analysis. The authors assessed the domain-specific form of teacher self-efficacy. All of these results have a descriptive level of conclusiveness. Most of the publications were rated as moderate in quality; thus, differences in the results cannot be explained by systematic differences in quality or study design.

Teachers' intervention strategies. (10 studies) Gregus et al. (2017) presented four different teacher strategies (e.g., speaking to the victim) and built an overall score for the use of these strategies. In both studies presented by the authors, teachers with higher self-efficacy beliefs scored higher in their intention to use these strategies (Gregus et al. 2017). Boulton et al. (2014) reported that teachers with a higher self-efficacy for using cognitive-behavioral strategies used these strategies more often. This is the only result with an indicative level of conclusiveness. In the data presented by Novick and Isaacs (2010), teachers who felt more confident in managing bullying reported higher scores in coaching students in handling bullying and in supporting students to prevent bullying.

For the other studies, the results on the connection between teachers' self-efficacy and their use of particular intervention strategies were much less clear. Newman (2010) found that teachers with higher self-efficacy talked more often to both bullying and bullied students and less often ignored situations of social exclusion than teachers with lower self-efficacy. When it came to physical or verbal bullying, as well as using punishment as an intervention strategy, no connections to self-efficacy were found. Nappa et al. (2018) reported that the bullying-specific form of self-efficacy was positively connected to teachers' "feeling of powerlessness" (p. 211) in bullying situations, while the domain-specific form of teacher self-efficacy was positively connected to the "positive activation" ( $p$. 211; e.g., speaking to the bullied students and understanding their needs) of teachers. 
Four more studies found no connection at all between teachers' self-efficacy and their choices of intervention strategies. This was the case for three different forms of assessment for intervention strategies used by the teachers under study. In two studies, teachers were asked how they would react in a hypothetical bullying situation and were able to choose from a list of strategies (Coffee 2005) or were asked about their intended usage of different presented strategies (Begotti et al. 2018). In a third study, teachers were asked to freely describe their intervention to a hypothetical bullying situation (Yoon 2004). In a fourth study, teachers were able to choose from a list of intervention strategies to indicate how they did react to a bullying situation in the past that they had actually experienced (Bilz and Kunze 2017).

Students' bullying behavior and victimization experiences. Students' experiences of victimization. (6 studies) Most results indicated that teachers' self-efficacy was not connected to their students' self-reported experiences of being bullied (De Luca et al. 2019; Fischer 2018; Guimond et al. 2015; Khoury-Kassabri 2011; Swift 2016) or the teachers' perceptions of the frequency of victimization (Gregus et al. 2017; Swift 2016). Other results suggested that the students of teachers with higher levels of self-efficacy may feel less verbally victimized, but not less victimized in general, nor less victimized in other bullying forms (Gregus et al. 2017), nor feel that their classmates are less victimized (Swift 2016). However, some of these results did not consider the multilevel structure of the data (Guimond et al. 2015; Swift 2016). Nonmultilevel analysis methods may lead to an underestimation of standard errors and in turn bias findings, meaning that some of these results should be approached with caution. Four studies reported results from multilevel analyses on teachers' selfefficacy and students' experiences of victimization (De Luca et al. 2019; Fischer 2018; Gregus et al. 2017; KhouryKassabri 2011) and also found no significant connections.

Students' bullying behavior. (3 studies) Correlational analyses presented by Swift (2016) suggest no connections between teachers' self-efficacy and students' bullying behavior as perceived by teachers, students, or their classmates. Using multilevel analyses, Fischer (2018) suggested that students whose class teachers are more self-confident bully others less often. In contrast to this result, Begotti et al. (2018) found no significant connection between teachers' self-efficacy and their students' bullying behavior in a path analysis. Both studies assessed different forms of self-efficacy. In the study presented by Fischer (2018), task-specific bullying-related selfefficacy was analyzed. Begotti et al. (2018) assessed domainspecific teacher self-efficacy.

Collective efficacy. (1 study) The authors found that students whose teachers feel higher levels of collective efficacy bully others less often, both traditionally and online, and experience less cyberbullying, but not less traditional bullying (Olsson et al. 2017). In contrast to the results on teachers' individual self-efficacy, these results were rated as being high in quality.

Prevention strategies. (2 studies) In one study, the selfefficacy of teachers was not connected to the time that the teachers actually spent on the implementation of the KiVa anti-bullying program (originally developed by Salmivalli and colleagues for schools in Finland) or the amount of lessons they gave on it (Swift 2016/Swift et al. 2017). In the second study that addressed this topic, Cecil and MolnarMain (2015) found that teachers with higher self-efficacy beliefs implemented the Olweus Bullying Prevention Program more extensively. When interpreting these results, it must be noted that each of these studies assessed a different form of self-efficacy. While Cecil Molnar-Main (2015) looked very specifically at teachers' self-efficacy in terms of their ability to implement the prevention program in question, Swift (2016, also presented in Swift et al. 2017) assessed a more general domain-specific form of teacher self-efficacy.

Other bullying-related outcomes. Beyond the findings presented, one study also investigated a connection between teachers' self-efficacy and goal-setting in bullying interventions (Bilz and Kunze 2017). The authors found that teachers with higher self-efficacy beliefs had a higher number of intervention goals. Teachers with higher self-efficacy beliefs also reported higher levels of goal attainment. But when their students were surveyed, they did not report that teachers with higher self-efficacy beliefs were more successful in their bullying interventions.

Summary of results on the connection to bullying-related outcomes. In summary, results indicate that teachers with higher self-efficacy beliefs intervene more often in bullying situations. They may use more intervention strategies than colleagues with lower self-efficacy beliefs, but no clear pattern of influence on favored strategies can be identified. Teachers' self-efficacy beliefs do not seem to be reflected in students' experiences of victimization. Because of the very limited research in this field, it is not clear if students of teachers with higher self-efficacy beliefs bully others less often. Teachers who are more confident when it comes to their ability to prevent bullying may be more committed to prevention programs, but there is not enough research to fully assess this.

\section{Discussion}

Previous research has identified teachers' self-efficacy as a competence that is important for bullying prevention and intervention. The literature on self-efficacy in the context of bullying among students is varied and addresses several topics and research questions. Results on teachers' bullying-related self-efficacy and teachers' bullying-related collective efficacy were identified in 36 publications, based on 33 studies. 


\section{Quality of the Results and Theoretical Foundation}

Most results were of low or very low quality, indicating that the theoretical foundation or methodological assessment was not sufficiently described or employed in the study in question. Many papers were missing a clear definition or explanation of what self-efficacy is. If the theoretical basis and underlying understanding of self-efficacy is not clear, then it inevitably becomes difficult to compare results (Schmitz and Schwarzer 2000; Tschannen-Moran and Woolfolk Hoy 2001). As self-efficacy is assessed differently in the context of a variety of disciplines, one could argue that a multifaceted understanding of the concept in the literature is in fact not a weakness, but a strength. However, it does increase the necessity for each publication to explicitly explain its underlying understanding of self-efficacy.

Another reason for results being evaluated as being of low or very low quality is that they are often based on relatively small sample sizes, which in turn narrows the validity of the results. Ryan and Hill (2016), for instance, suggest that results should be based on at least 300 participants for dichotomous outcomes and 400 participants for continuous outcomes. As these specifications were formulated for individual data, data with a multilevel structure, such as school data, should be based on even larger sample sizes. But only four out of the 33 studies are based on samples with 500 or more participants. Future research should include larger sample sizes in order to reach sufficient power and informative value. Furthermore, all but one study uses correlational study designs. More valid findings could be obtained with data from longitudinal or (quasi-)experimental designs.

\section{General Extent and Group Differences}

Teachers reported feeling generally confident in managing bullying. According to Bandura (1994), positive experiences with mastered challenges are one of the main sources of selfefficacy. Due to the high prevalence of bullying (Modecki et al. 2014), one might assume that most teachers have been confronted with bullying at some point in their working lives and reacted to it in some way (Wachs et al. 2019). This may indeed be especially true for teachers who voluntarily take part in a survey on bullying, as they may have a special interest in the topic.

However, in qualitative studies, teachers report feeling much less confident in managing bullying among students. Because of the low number of qualitative studies that could be included in this review, it is possible that the different levels of self-efficacy expressed in quantitative and qualitative studies are based on chance alone. But another possible explanation is that teachers may feel more motivated to report their own insecurities in personal interviews, which may be more detailed than written surveys. Written surveys tend to use hypothetical, prototypical bullying situations, which may produce overrated and positively biased levels of confidence. To our knowledge, there is no study that assesses the level of selfefficacy in teachers in both written surveys and in interviews. It would be interesting to see if the research approach itself influences the levels of self-efficacy expressed.

The generally high levels of self-efficacy found in these studies seem to contradict findings that teachers commonly want more training in bullying prevention and intervention than they are receiving (Blain-Arcaro et al. 2012; Kennedy et al. 2012). A possible explanation may lie in differences in types of bullying. Teachers may, for instance, feel less confident in handling cyberbullying, bullying outside school grounds, bullying of students with disabilities, and in working with students who bully. When reporting that they feel illprepared and expressing a desire for more training in this field, teachers may have had these types of bullying in mind. In addition, it is possible that teachers feel confident in handling bullying because of personal experiences, but still wish to be trained systematically in bullying prevention and intervention.

\section{Likelihood of Intervention and Intervention Strategies}

As teachers can play a key role in bullying situations (Oldenburg et al. 2015; Saarento et al. 2015), it is important that they intervene when it occurs among students. With research showing that teachers who are more confident intervening more often in these situations, teachers' self-efficacy should be increased using specific in-service and pre-service teacher-training interventions, which should in turn be researched further.

However, when interpreting the connection between teachers' self-efficacy and the likelihood that they will intervene in bullying it has to be noted that all the results from the studies under review stem from descriptive study designs. Therefore, it is impossible to say whether higher levels of self-efficacy increase the likelihood of intervention. It is instead likely that teacher intervention competences (including self-efficacy) and teachers' intervention behavior interact with each other (Bilz et al. 2017; Fischer and Bilz 2019b). Higher levels of confidence may lead teachers to intervene in bullying situations more often, and the experience of having intervened successfully (from the teachers' subjective point of view, at least) may enhance teachers' selfefficacy (Bandura 1994). Longitudinal study designs are needed in order to assess the causal effect that self-efficacy may have on the likelihood that teachers will intervene in bullying situations.

The topic that was investigated most often in the studies identified is the connection between teachers' self-efficacy and their choice of intervention strategy. How intervention strategies were specifically assessed and which particular strategies were investigated is correspondingly heterogeneous. When looking at the number of strategies that teachers utilize in bullying situations, results show that teachers with higher self-efficacy beliefs use a 
higher number of strategy types and, consequently, a broader range of strategies. Teachers who have a greater repertoire of intervention strategies are more flexible in intervening, can adapt their interventions better to specific incidents of bullying, and they are also better able to deal with the complexity of bullying situations. It is, therefore, possible that teachers with higher selfefficacy beliefs are also more successful in bullying interventions. This has, however, only been investigated a single time in the literature. Whether or not teachers with higher self-efficacy beliefs are, in fact, more successful in their interventions is a question that needs further investigation. Existing results show no specific preferences among teachers for particular intervention strategies based on their self-efficacy beliefs. In other words, teachers' self-efficacy seems to be connected to the likelihood that they will intervene in bullying situations and to the number of intervention strategies they will use, but not to which specific intervention strategies they will employ.

\section{Students' Bullying Behavior and Experiences of Victimization}

The results that were identified in this review indicate that teachers' self-efficacy is not connected to students' experiences of victimization. When it comes to active bullying behaviors in students, the data is very scant. One study that reported that students whose teachers have higher levels of self-efficacy bully others less often is of higher quality than two other studies that found no such connection. Besides, a task-specific bullying-related form of self-efficacy was assessed in this study, while domain-specific teacher selfefficacy was assessed in the two studies that found no associations. The assessment of self-efficacy in a specific form is often recommended (Bandura 1977; Schmitz and Schwarzer 2000; Tschannen-Moran and Woolfolk Hoy 2001). So, one could assume that teachers with higher self-efficacy beliefs may influence students to bully others less often. But further research is needed on this connection.

The same is true for teachers' collective efficacy. The authors of the only study that investigated this topic linked collective efficacy with shared norms that help prevent bullying (Olsson et al. 2017). The importance of shared norms and cooperative intervention structures is repeatedly stressed in bullying research (e.g., Saarento et al. 2015; Wachs et al. 2019). Against this background, the importance and role of collective efficacy should also be researched further.

\section{Prevention Strategies}

Because the data is very scant, it cannot be said with any certainty whether or not teachers with higher self-efficacy beliefs implement anti-bullying programs more intensively. This is especially problematic when one considers that both prevention and intervention are important in successful anti- bullying strategies. Prevention, which is important in lowering the risk of acute bullying incidents, should also include intervention strategies that learn from real bullying situations in order to reduce them in the future. Therefore, future research should place more emphasis on those factors that help teachers successfully prevent bullying.

\section{Limitations}

Only publications that were published in English or German were included in the review. It is possible that other relevant findings could not be considered because of this.

Because the adaptation of quality criteria by Cochrane and Green List Prevention was developed for quantitative studies, the quality of the qualitative studies was not assessed in this review. Despite the fact that the number of qualitative studies included in this review were small, this nevertheless does limit the integration and interpretation of these findings.

The common definition of bullying by Olweus was used in this study. Consequently, cyberbullying was defined as online bullying that meets the criteria presented by Olweus. However, the definition of bullying and especially cyberbullying as well as their similarities and differences are controversial (Dooley et al. 2009; Kofoed and Staksrud 2019). In this review, cyberbullying was seen as a form of bullying. Whenever differences in the identified results occurred, these differences were presented in the review. Future research may place a stronger emphasis on cyberbullying in particular in order to identify findings that may be unique to this type of bullying.

\section{Practical Implications}

This review of empirical studies supports the idea that teachers with higher self-efficacy tend to intervene more often in bullying situations among students than teachers with lower selfefficacy. As teacher interventions can help stop students from bullying others, it is important that teachers' confidence in their own capabilities becomes a key part of their ongoing professional training for both pre-service and in-service teachers.

Research on teacher training shows that the use of video feedback can increase teachers' general self-efficacy (Gröschner et al. 2018). A conversational culture needs to be developed by those leading this training in order to create an atmosphere in which participants can discuss experienced situations, videos, and alternative reactions openly, critically, and respectfully (Alles et al. 2019).

Training should include both informational and interactive elements. Several studies, most of which used quasiexperimental designs, have tested teacher training on bullying interventions and their effects on teachers' self-efficacy. Results show that information on bullying, bullying prevention, and intervention strategies can increase teachers' self- 
efficacy (Benítez et al. 2009; Dedousis-Wallace et al. 2014; Greytak et al. 2013; Newman-Carlson and Horne 2004; Schultes et al. 2014). However, simply presenting information to teachers should be avoided when introducing research into practical teacher training, with interactive methods being favored instead (Rohrbach et al. 2006). In doing so, teachers can be confronted with case studies on bullying and then be motivated to discuss similar situations that they have experienced with their own students (Boulton 2014; Dedousis-Wallace et al. 2014; Greytak et al. 2013). They might also discuss real-life bullying situations with each other and reflect on alternative responses in individual or ongoing supervisory groups (Bell et al. 2010; Newman-Carlson and Horne 2014). Also found to be successful in increasing teachers' bullying self-efficacy were encouraging them to discuss intervention strategies they have used and found effective (DedousisWallace et al. 2014) and the use of role-play to practice the professional behaviors discussed during the training (Bell et al. 2010; Greytak et al. 2013). A number of studies have suggested that these methods have been successful in increasing both teachers' self-efficacy and the likelihood that they will intervene in bullying situations (Dedousis-Wallace et al. 2014; Newman-Carlson and Horne 2004).

\section{Conclusion}

In the present systematic review, findings on the extent and group differences of teachers' bullying-related self-efficacy and its connections to teachers' bullying prevention and intervention were compiled and systematized. It was found that several studies addressed these connections with a wide range of topics emerging. Teachers often reported relatively high levels of self-efficacy. This is an especially important result, as several studies show that teachers who are more confident in managing bullying intervene more often in bullying situations. Over the past few years, the interest in the connection between bullying and the self-efficacy of teachers has increased, but current findings are often based on individual studies. Most results also come from descriptive studies and many are of low or very low theoretical and methodological quality. These studies are often missing an explicitly defined understanding of self-efficacy or are based on small sample sizes. Quite heterogeneous findings exist on the connection between teachers' self-efficacy and their choice of intervention strategies, the effort they put into prevention, as well as their students' bullying behaviors and their experience of being victimized. Future studies are needed to validate existing individual findings and to explain the differences that exist in the results.

Funding Information Open Access funding provided by Projekt DEAL.

\section{Compliance with Ethical Standards}

Conflict of Interest The authors declare that there is no conflict of interest.

Open Access This article is licensed under a Creative Commons Attribution 4.0 International License, which permits use, sharing, adaptation, distribution and reproduction in any medium or format, as long as you give appropriate credit to the original author(s) and the source, provide a link to the Creative Commons licence, and indicate if changes were made. The images or other third party material in this article are included in the article's Creative Commons licence, unless indicated otherwise in a credit line to the material. If material is not included in the article's Creative Commons licence and your intended use is not permitted by statutory regulation or exceeds the permitted use, you will need to obtain permission directly from the copyright holder. To view a copy of this licence, visit http://creativecommons.org/licenses/by/4.0/.

\section{References}

References marked with asterisk are included in the review.

Alles, M., Seidel, T., \& Gröschner, A. (2019). Establishing a positive learning atmosphere and conversation culture in the context of a video-based teacher learning community. Professional Development in Education, 45(2), 250-263.

Azeredo, C. M., Rinaldi, A. E. M., De Moraes, C. L., Levy, R. B., \& Menezes, P. R. (2015). School bullying: a systematic review of contextual-level risk factors in observational studies. Aggression and Violent Behavior, 22, 65-76.

Bandura, A. (1977). Self-efficacy: toward a unifying theory of behavioural change. Psychological Review, 84, 191-215.

Bandura, A. (1994). Self-efficacy. In V. S. Ramachaudran (Ed.), Encyclopedia of Human Behavior (pp. 71-81). Academic Press.

Begotti, T., Tirassa, M., \& Maran, D. A. (2017). School bullying episodes: attitudes and intervention in pre-service and in-service Italian teachers. Research Papers in Education, 32(2), 170-182.

*Begotti, T., Tirassa, M., \& Maran, D. A. (2018). Pre-service teachers' intervention in school bullying episodes with special education needs students: a research in Italian and Greek samples. International Journal of Environmental Research and Public Health, 15(9), 1908.

Bell, C. D., Raczynski, K. A., \& Horne, A. M. (2010). Bully busters abbreviated: evaluation of a group-based bully intervention and prevention program. Group Dynamics: Theory, Research, and Practice, 14(3), 257-267.

Benítez, J. L., García-Berbén, A., \& Fernández-Cabezas, M. (2009). The impact of a course on bullying within the pre-service teacher training curriculum. Electronic Journal of Research in Educational Psychology, 7(1), 191-208.

*Bilz, L., \& Kunze, U. (2017). Der Zusammenhang zwischen Selbstwirksamkeitserwartung und Lehrerinterventionen bei Mobbing [The connection between self-efficacy and intervention of teachers in bullying]. In L. Bilz, W. Schubarth, I. Dudziak, S. M. Fischer, S. Niproschke \& J. Ulbricht (Hrsg.), Gewalt und Mobbing an Schulen. Wie sich Gewalt und Mobbing entwickelt haben, wie Lehrer intervenieren und welche Kompetenzen sie brauchen (pp. 219-229). Verlag Julius Klinkhardt.

Bilz, L., Schubarth, W., Dudziak, I., Fischer, S. M., Niproschke, S., \& Ulbricht, J. (2017). Gewalt und Mobbing an Schulen. Wie sich Gewalt und Mobbing entwickelt haben, wie Lehrer intervenieren 
und welche Kompetenzen sie brauchen [Violence and bullying in schools. How violence and bullying have developed, how teachers intervene and what skills they need]. Verlag Julius Klinkhardt.

Blain-Arcaro, C., Smith, J. D., Cunningham, C. E., Vaillancourt, T., \& Rimas, H. (2012). Contextual attributes of indirect bullying situations that influence teachers' decisions to intervene. Journal of School Violence, 11(3), 226-245.

*Boulton, M. J. (2014). Teachers' self-efficacy, perceived effectiveness beliefs, and reported use of cognitive-behavioral approaches to bullying among pupils: effects of in-service training with the I DECIDE program. Behavior Therapy, 45(3), 328-343.

*Boulton, M. J., Hardcastle, K., Down, J., Fowles, J., \& Simmonds, J. A. (2014). A comparison of preservice teachers' responses to cyber versus traditional bullying scenarios: similarities and differences and implications for practice. Journal of Teacher Education, 65(2), $145-155$.

Bradshaw, C. P., Sawyer, A. L., \& O'Brennan, L. M. (2007). Bullying and peer victimization at school: perceptual differences between students and school staff. School Psychology Review, 36(3), 361382.

Camodeca, M., Caravita, S. C. S., \& Coppola, G. (2015). Bullying in preschool: the associations between participant roles, social competence, and social preference. Aggressive Behavior, 41, 310-321.

*Cecil, H., \& Molnar-Main, S. (2015). Olweus bullying prevention program: components implemented by elementary classroom and specialist teachers. Journal of School Violence, 14(4), 335-362.

*Coffee, A. W. (2005). The influence of personal and environmental factors on teacher preference for intervention in student altercations. Dissertation. Honolulu: University of Hawaii.

*Collier, K. L., Bos, H. M. W., \& Sandfort, T. G. M. (2015). Understanding teachers' responses to enactments of sexual and gender stigma at school. Teaching and Teacher Education, 48, 34-43.

*De Luca, L., Nocentini, A., \& Menesini, E. (2019). The teachers' role in preventing bullying. Frontiers in Psychology, 10, 1830.

*Dedousis-Wallace, A., Shute, R., Varlow, M., Murrihy, R., \& Kidman, T. (2014). Predictors of teacher intervention in indirect bullying at school and outcome of a professional development presentation for teachers. Educational Psychology, 34(7), 862-875.

*Doherty, E. N. (2009). Self-efficacy and relational aggression: an examination of general and special education teachers. Dissertation. San Diego: Alliant International University San Diego.

Dooley, J. J., Pyżalski, J., \& Cross, D. (2009). Cyberbullying versus faceto-face bullying. A theoretical and conceptual review. Zeitschrift für Psychologie, 217(4), 182-188.

Duong, J., \& Bradshaw, C. P. (2013). Using the extended parallel process model to examine teachers' likelihood of intervening in bullying. Journal of School Health, 83(6), 422-429.

*Farley, J. (2016). The obligated bystander: an analysis of factors which influence teacher intervention in school bullying. Dissertation. Ames: Iowa State University.

*Farley, J. (2018). Teachers as obligated bystanders: grading and relating administrator support and peer response to teacher direct intervention in school bullying. Psychology in the Schools, 55(9), 10561070.

*Fischer, S. M. (2018). Erfolg erwarten und erfolgreich handeln: Die Selbstwirksamkeitserwartung von Lehrkräften, ihre Interventionswahrscheinlichkeit in realen Mobbingsituationen und die Mobbingerfahrungen ihrer Schülerinnen und Schüler [Expect success and act successfully: The self-efficacy expectations of teachers, their probability of intervention in real bullying situations, and the bullying experiences of their students]. Presentation at 51th DGPs-Congress, 17.-20. September 2018, Frankfurt am Main, Germany. https://osf.io/view/DGPs2018/ [22.05.2020].

*Fischer, S. M., \& Bilz, L. (2019a). Teachers' self-efficacy in bullying interventions and their probability of intervention. Psychology in the Schools, 56(5), 751-764.
Fischer, S. M., \& Bilz, L. (2019b). Is self-regulation a relevant aspect of intervention competence for teachers in bullying situations? Nordic Studies in Education, 39(2), 121-141.

*Fischer, S. M., Ulbricht, J., \& Bilz, L. (2017). Skala zur Erfassung der mobbingbezogenen Selbstwirksamkeitserwartung von Lehrkräften $\left(M O B \_W K\right)$ [Scale for recording the bullying-related self-efficacy of teachers]. Zusammenstellung sozialwissenschaftlicher items und Skalen. https://search.gesis.org/instruments_tools/zis251 [22.05. 2020].

*Garner, P. W. (2017). The role of teachers' social-emotional competence in their beliefs about peer victimization. Journal of Applied School Psychology, 33(4), 288-308.

Gini, G., \& Pozzoli, T. (2013). Bullied children and psychosomatic problems: a meta-analysis. Pediatrics, 132, 720-729.

*Gregus, S. J., Rodriguez, J. H., Pastrana, F. A., Craig, J. T., McQuillin, S. D., \& Cavell, T. A. (2017). Teacher self-efficacy and intentions to use antibullying practices as predictors of children's peer victimization. School Psychology Review, 46(3), 304-319.

Greytak, E. A., Kosciw, J. G., \& Boesen, M. J. (2013). Educating the educator: creating supportive school personnel through professional development. Journal of School Violence, 12(1), 80-97.

Gröschner, A., Schindler, A.-K., Holzberger, D., Alles, M., \& Seidel, T. (2018). How systematic video reflection in teacher professional development regarding classroom discourse contributes to teacher and student self-efficacy. International Journal of Educational Research, 90, 223-233.

*Guimond, F.-A., Brendgen, M., Vitaro, F., Dionne, G., \& Boivin, M. (2015). Peer victimization and anxiety in genetically vulnerable youth: the protective roles of teachers' self-efficacy and antibullying classroom rules. Journal of Abnormal Child Psychology, 43(6), 1095-1106.

*Hazeltine, C. S. (2018). Understanding teachers' perceptions of bullying for developing teacher detection and intervention. Dissertation. Minneapolis: Walden University.

Hong, J. S., \& Espelage, D. L. (2012). A review of research on bullying and peer victimization in school: an ecological system analysis. Aggression and Violent Behavior, 17, 311-322.

Hymel, S., McClure, R., Miller, M., Shumka, E., \& Trach, J. (2015). Addressing school bullying: insights from theories of group processes. Journal of Applied Developmental Psychology, 37, 16-24.

Kennedy, T. D., Russom, A. G., \& Kevorkian, M. M. (2012). Teacher and administrator perceptions of bullying in schools. International Journal of Education Policy \& Leadership, 7(5), 1-12.

*Khoury-Kassabri, M. (2011). Student victimization by peers in elementary schools: individual, teacher-class, and school-level predictors. Child Abuse \& Neglect, 35(4), 273-282.

Klomek, A. B., Kleinman, M., Altschuler, E., Marrocco, F., Amakawa, L., \& Gould, M. S. (2013). Suicidal adolescents' experiences with bullying perpetration and victimization during high school as risk factors for later depression and suicidality. Journal of Adolescent Health, 53, S37-S42.

Kofoed, J., \& Staksrud, E. (2019). 'We always torment different people, so by definition, we are no bullies': the problem of definitions in cyberbullying research. New Media \& Society, 21(4), 1006-1020.

Landespraeventionsrat Niedersachsen. (2011). Auswahl- und Bewertungskriterien für die CTC Programm-Datenbank [Selection and evaluation criteria for the CTC program database]. https://www. gruene-liste-praevention.de/communities-that-care/Media/Grne Liste_Bewertungskriterien.pdf [22.05.2020].

*Lay, D. J. (2010). Exploring how teachers' personal experiences with childhood bullying influence their response to student bullying. Dissertation. Phoenix: University of Phoenix.

*Maynes, N., \& Mottonen, A.-L. (2017). Bullying in schools: are preservice teachers confident to address this? Alberta Journal of Educational Research, 63(4), 396-411. 
Modecki, K. L., Minchin, J., Harbaugh, A. G., Guerra, N. G., \& Runions, K. C. (2014). Bullying prevalence across contexts: a meta-analysis measuring cyber and traditional bullying. Journal of Adolescent Health, 55, 602-611.

*Nappa, M. R., Palladino, B. E., Menesini, E., \& Baiocco, R. (2018). Teachers' reaction in homophobic bullying incidents: the role of self-efficacy and homophobic attitudes. Sexuality Research and Social Policy, 15(2), 208-218.

*Newman, J. B. (2010). Teacher interventions in bullying situations: perceptions of middle school students and teachers. Dissertation. Seattle: University of Washington.

Newman-Carlson, D., \& Horne, A. M. (2004). Bully busters: a psychoeducational intervention for reducing bullying behavior in middle school students. Journal of Counseling \& Development, 82, 259-267.

*Nicolaides, S., Toda, Y., \& Smith, P. K. (2002). Knowledge and attitudes about school bullying in trainee teachers. British Journal of Educational Psychology, 72, 105-118.

*Novick, R. M., \& Isaacs, J. (2010). Telling is compelling: the impact of student reports of bullying on teacher intervention. Educational Psychology, 30(3), 283-296.

Oldenburg, B., van Duijn, M., Sentse, M., Huitsing, G., van der Ploeg, R., Salmivalli, C., \& Veenstra, R. (2015). Teacher characteristics and peer victimization in elementary schools: a classroom-level perspective. Journal of Abnormal Child Psychology, 43, 33-44.

*Olsson, G., Lâftman, S. B., \& Modin, B. (2017). School collective efficacy and bullying behaviour: a multilevel study. International Journal of Environmental Research and Public Health, 14(1607), $1-12$.

Olweus, D. (1994). Annotation: Bullying at school: basic facts and effects of a school based intervention program. Journal of Child Psychology and Psychiatry, 35, 1171-1190.

*Purdy, N., \& Mc Guckin, C. (2014). Disablist bullying in Northern Ireland and the Republic of Ireland: an investigation of student teachers' knowledge, experience and confidence. European Journal of Special Needs Education, 29(4), 446-456.

*Purdy, N., \& Mc Guckin, C. (2015). Disablist bullying in schools: giving a voice to student teachers. Journal of Research in Special Educational Needs, 15(3), 202-210.

Rohrbach, L. A., Grana, R., Sussman, S., \& Valente, T. W. (2006). Type II translation - transporting prevention interventions from research to real-world settings. Evaluation \& the Health Professions, 29(3), 302-333.

Ryan, R., \& Hill, S. (2016). How to GRADE the quality of the evidence Version 3.0 December 2016. Cochrane Consumers and Communication Group. http://cccrg.cochrane.org/author-resources [22.05.2020].

*Ryan, T., Kariuki, M., \& Yilmaz, H. (2011). A comparative analysis of cyberbullying perceptions of preservice educators: Canada and Turkey. Turkish Online Journal of Educational Technology, 10(3), $1-12$.

Saarento, S., Garandeau, C. F., \& Salmivalli, C. (2015). Classroom- and school-level contributions to bullying and victimization: a review. Journal of Community \& Applied Social Psychology, 25(3), 204 218.

Schmitz, G. S., \& Schwarzer, R. (2000). Selbstwirksamkeitserwartung von Lehrern: Längsschnittbefunde mit einem neuen instrument [Self-efficacy of teachers: longitudinal results with a new measure]. Zeitschrift für Pädagogische Psychologie, 14, 12-25.

Scholz, U., Doña, B. G., Sud, S., \& Schwarzer, R. (2002). Is general selfefficacy a universal construct? Psychometric findings from 25 countries. European Journal of Psychological Assessment, 18, 242-251.
Schultes, M.-T., Stefanek, E., Van de Schoot, R., Strohmeier, D., \& Spiel, C. (2014). Measuring implementation of a school-based violence prevention program. Fidelity and teachers' responsiveness as predictors of proximal outcomes. Zeitschrift für Psychologie, 222(1), 49-57.

Schwarzer, R., \& Jerusalem, M. (2002). Das Konzept der Selbstwirksamkeit [The concept of self-efficacy]. Zeitschrift für Pädagogik, 44. Beiheft, 28-53.

Schwarzer, R., \& Warner, L. M. (2014). Forschung zur Selbstwirksamkeit bei Lehrerinnen und Lehrern [Research on selfefficacy of teachers]. In E. Terhart, H. Bennewitz \& M. Rothland (Hrsg.), Handbuch der Forschung zum Lehrerberuf (pp. 662-678). Waxmann

*Song, K.-H., Lee, S.-Y., \& Park, S. (2018). How individual and environmental factors influence teachers' bullying intervention. Psychology in the Schools, 55(9), 1086-1097.

Stiftung Deutsches Forum für Kriminalpraevention. (2018). Entwicklungsförderung und Gewaltprävention für junge Menschen [Promotion of development and prevention of violence for young people]. https://www.wegweiser-praevention.de/files/DFK/dfkpublikationen/2018_leitfaden_e_und_g.pdf [22.05.2020].

*Swift, L. E. (2016). Teacher factors contributing to implementation of the KiVa anti-bullying program. Dissertation. Newark: University of Delaware.

*Swift, L. E., Hubbard, J. A., Bookhout, M. K., Grassetti, S. N., Smith, M. A., \& Morrow, M. T. (2017). Teacher factors contributing to dosage of the KiVa anti-bullying program. Journal of School Psychology, 65, 102-115.

Takizawa, R., Maughan, B., \& Arseneault, L. (2014). Adult health outcomes of childhood bullying victimization: evidence from a five decade longitudinal British birth cohort. American Journal of Psychiatry, 171, 777-784.

*Thomas, T. W. (2017). An analysis of teachers' perceptions of bullying at the elementary school level. Dissertation. Minneapolis: Walden University.

Tschannen-Moran, M., \& Woolfolk Hoy, A. (2001). Teacher efficacy: capturing an elusive construct. Teaching and Teacher Education, 17, 783-805.

*VanZoeren, S., \& Weisz, A. N. (2018). Teachers' perceived likelihood of intervening in bullying situations: individual characteristics and institutional environments. Journal of School Violence, 17(2), 258269.

Veerman, J. W., \& Van Yperen, T. A. (2007). Degrees of freedom and degree of certainty: a developmental model for the establishment of evidence-based youth care. Evaluation and Program Planning, 30, 212-221.

Wachs, S., Bilz, L., Niproschke, S., \& Schubarth, W. (2019). Bullying intervention in schools: a multilevel analysis of teachers' success in handling bullying from the students' perspective. Journal of Early Adolescence, 39(5), 642-668.

Williford, A., \& Depaolis, K. J. (2016). Predictors of cyberbullying intervention among elementary school staff: the moderating effect of staff status. Psychology in the Schools, 53(10), 1032-1044.

*Yoon, J. S. (2004). Predicting teacher interventions in bullying situations. Education and Treatment of Children, 27(1), 37-45.

Yoon, J., Sulkowski, M. L., \& Bauman, S. A. (2016). Teachers' responses to bullying incidents: effects of teacher characteristics and contexts. Journal of School Violence, 15(1), 91-113.

Zee, M., \& Koomen, H. M. Y. (2016). Teacher self-efficacy and ist effects on classroom processes, student academic adjustment, and teacher well-being: a synthesis of 40 years of research. Review of Educational Research, 86(4), 981-1015. 